\title{
The model of localized business community economic development under limited financial resources: computer model and experiment
}

\author{
Dmitry Berg ${ }^{1 \mathrm{a}}$, Rustam Davletbaev ${ }^{1}$, Olga Zvereva ${ }^{1}$, and Dmitry Nodjenko ${ }^{2}$ \\ ${ }^{1}$ Ural Federal University, 620002, Yekaterinburg, Russia \\ ${ }^{2}$ Institute of Economics, Ural Branch of RAS, 620014, Yekaterinburg, Russia
}

\begin{abstract}
Globalization processes now affect and are affected by most of organizations, different type resources, and the natural environment. One of the main restrictions initiated by these processes is the financial one: money turnover in global markets leads to its concentration in the certain financial centers, and local business communities suffer from the money lack. This work discusses the advantages of complementary currency introduction into a local economics. By the computer simulation with the engineered program model and the real economic experiment it was proved that the complementary currency does not compete with the traditional currency, furthermore, it acts in compliance with it, providing conditions for the sustainable business community development.
\end{abstract}

\section{Introduction}

Globalization processes, which concepts were established only in the $70 \mathrm{~s}$ of the last century, now affect and are affected by business and work organizations, economics, sociocultural resources, and the natural environment. Large-scale globalization began in the nineteenth century [1] and was accompanied both by positive and negative phenomena in trade and transactions, capital and investment movements, migration and movement of people [2]. Real threats of globalization stimulated the anti-globalist movement and development of the glocalization vision (glocalization is a portmanteau of globalization and localization). The last one provides city-to-city cooperation; encouraging peace building and international development in the non-governmental sector. It emphasizes the central role of cities in international relations and the role of local authorities in the world governance system $[3,4]$.

One of the main restrictions, the local business community is faced by, is the financial one: money turnover in global markets leads to its concentration in the certain financial centers, which are far away from local communities. Local economic activity is inhibited because of the money lack: economic communications between agents (their goods and products exchange) are hampered and becomes more difficult. This problem arises all over the world and local communities try to overcome it using such instruments as bills

\footnotetext{
a Corresponding author: Bergd@mail.ru
} 
of exchange, barter systems, local exchange trading systems (LETS), different types of complementary currencies, and etc. [5].

The main goal of the present study is to demonstrate the positive effect of complementary currency usage in the local economic turnover which is provided for sustainable development of the local business community. The effect proposed is shown in computer simulation using the local community communications agent-based program model and is also confirmed by the real economic experiment.

\section{Local community communications model}

To prove the concepts discussed above communications program model was engineered. In the modeled system several manufacturing entities have to produce some goods and in order to succeed in this activity try to supply themselves with resources in the specified volumes.

To design this model agent-based technology was used [6]. This technology is geared towards social sciences and is the most suitable for this problem solving [7]. It supports bottom-up approach: one should model agents, their interactions with each other and environment and observe the whole system parameters (macroparameters) as a result.

Agent's attributes were calculated on the base of Leonief's static equilibrium (InputOutput model) [8]. The Model was designed in Netlogo [9], free software framework, which supports the agent-based technology. Model window is shown in Figure 1.

In the Model there are $\mathrm{N}$ agents, every agent produces a unique product. The $i$-th agent product volume is denoted as $x_{i}$. The ordered sequence of all agent product volumes $\left(x_{i}, i=\right.$ $\overline{1, N)}$ forms $\left(\vec{X}=\left(x_{i}\right)_{i=1}^{N}\right)$, which is the production vector of the economic system under study.

The $i$-th agent consumes the other agent's products for manufacturing of his own product of value $x_{i}$. These consumption volumes are denoted as $w_{k i}$, where $w_{k i}$ indicates the $i$-th agent consumption of the $k$-th agent's product. Then $\vec{W}_{i}$ is the $i$-th agent consumption vector:

$$
\vec{W}_{i}=\left(w_{i k}\right)_{k=1}^{N}
$$

this vector lists the agent product volumes to be consumed by the $i$-th agent in order to manufacture his own product of value $x_{i}$.

Every consumption volume $\left(w_{k i}\right)$ is in direct proportion to $x_{i}$ and is determined by the $i$ th agent productive technology. Technical (input) coefficients estimated as $a_{k i}=\frac{w_{k i}}{x_{i}}$ are dimensionless. These coefficients $a_{k i}(k=\overline{1, N}, i=\overline{1, N})$ comprise structural matrix, or table $\left(A_{N x N}\right)$. Matrix element $a_{k i}$ determines the $k$-th agent's product volume which is consumed by the $i$-th agent for its single product unit manufacturing.

Then the $i$-th agent consumption vector can be expressed as:

$$
\overrightarrow{\mathrm{W}}_{\mathrm{i}}=\left[a_{1 i} \cdot x_{i}, a_{2 i} \cdot x_{i}, \ldots, a_{n i} \cdot x_{i}\right],
$$

after product exchanges every agent has a remaining volume of his own product. Partly it can be used in his manufacturing process (this is reflected in $\vec{W}_{i}$ and the structural matrix) and the last part denoted as $y_{i}$ can be spent to meet the internal non-productive needs. Vector $\vec{Y}$ is known as a vector of final demands:

$$
\vec{Y}=\left(\mathrm{y}_{\mathrm{i}}\right)_{\mathrm{i}=1}^{\mathrm{N}}
$$

for the $i$-th agent it is true that: 


$$
x_{i}=a_{1 i} \cdot x_{1}+a_{2 i} \cdot x_{2}+\ldots+a_{N i} \cdot x_{N}+y_{i}
$$

Static form of Leontief's Equilibrium (SLE) is settled by the following vector equation:

$$
\vec{X}-A \vec{X}=\vec{Y}
$$

Leontief's static model has several limitations, one of them - this model describes a closed system. It means that all products are manufactured and consumed inside the system. This could be considered to be unrealistic. Modern economics is a global economics: a local economic system can't supply itself with all the necessary goods and install relations in the import-export form with other local communities.

Thus, the special agent was introduced into the model. This agent represents the environment in the system, per se it accumulates all the requirements in external resources, and all the shipments for external consumers. This agent, becoming the part of the system, corresponds to the requirements of SLE.

To support exchange operations in the model money was introduced. There are two types of currency in the system: external (real) currency and internal (complementary) currency. The external currency is money in its common sense. It can be used in all exchange operations simulated in the model and complementary currency is used only for internal exchanges, between all but the environmental agent.

Every agent has these currencies in its account, their volumes are in the direct proportion to its program and are calculated with the supplement coefficients $k$ mon (for real currency) and $k_{-} v$ vmon (for complementary currency). These coefficients can be set by special controls in the model window.

Simulation period is divided into cycles of exchange. In every cycle of exchange every agent receives an opportunity to buy one kind of resource according to its consumption vector. In the model five different exchange strategies are realized. In details they are discussed in $[10,11]$. In this experimental series the first "list" strategy was under research. In accordance to this strategy an agent is looking through its consumption list from the start to the end and tries to find and meet the first non-zero requirement in resources in the maximal possible value. After all the agents make their attempts, model time increases and new exchange cycle is initiated. Simulation lasts until any exchange is possible, i.e. there is a j-th agent $\left(P_{j}\right)$, who has non-zero $k$-th value in the current consumption list $\left(w_{k j} \neq 0\right)$ and non-zero sum of money, and, at the same time, there is a $k$-th agent has some product for sale (current value of $x_{k} \neq 0$ ).

$$
\left[\exists P_{j}, \exists P_{k}:\left(w_{k j} \neq 0\right) \wedge\left(m_{j} \neq 0\right) \wedge\left(x_{k} \neq 0\right)\right],
$$

The rule of money spending in exchange operation depends on the agent type and was already discussed.

Experiments were held using different data sets. These data sets are represented in Table 1.

Table 1. Data sets used in experiments

\begin{tabular}{|c|c|}
\hline Data Set & Structural Matrix (A) \\
\hline 1 & $\forall i=1 . .20, \forall j=1 . .20, \quad a_{i j}=0.0385$ \\
\hline 2 & $\forall i=1 . .20, \forall k=1 . .20, \sum_{i=1}^{20} a_{k i}=\sum_{i=1}^{20} a_{i k}=0.77$ \\
\hline 3 & $\left\{\begin{array}{l}\forall k=1 . .20: \sum_{i=1}^{20} a_{k i}=\sum_{i=1}^{20} a_{i k}=0.77 \\
\forall m=1 . .20, \forall n=1 . .20, a_{m n}=a_{n m}\end{array}\right.$ \\
\hline
\end{tabular}


In the first dataset all agents have equal consumption demands for products of the other agents, every structural matrix $(A)$ element is equal to 0,385 . The second dataset is made for the agents that have equal total demands for the other agents' products. And, in the third dataset, besides equal total agents' demands the condition of mutual demand equality is true (i.e. every $i$-th agent tries to consume the $k$-th agent product in the same volume as the $k$-th agent tries to consume the $i$-th agent product).

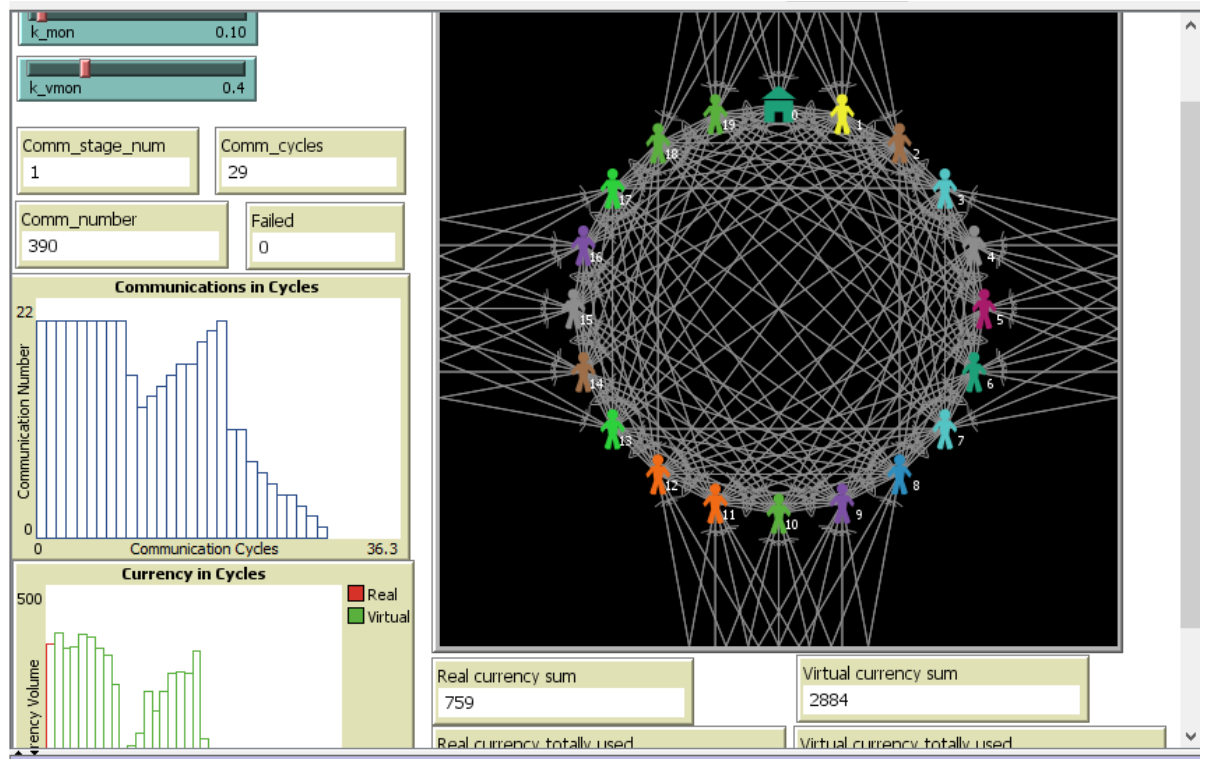

Fig. 1. Model window.

The experiments have proved:

- that if the model is based on the static Leontief's Equilibrium all exchanges are fulfilled successfully in all money conditions (if at least $\mathrm{k} \_$mon $>0$ );

- complementary currency existence in the system greatly decreases the time necessary for exchange completion, the complementary money "works" as the real money (it is apparent from Figure 2b );

- complementary currency weakens, and when it is enough, suppress the crisis (Figure 2a) which arises if money volume is insufficient in the system;

- the less real currency volume is in the system, the greater positive effect is made by the complementary currency introducing into the system (Figure 3).
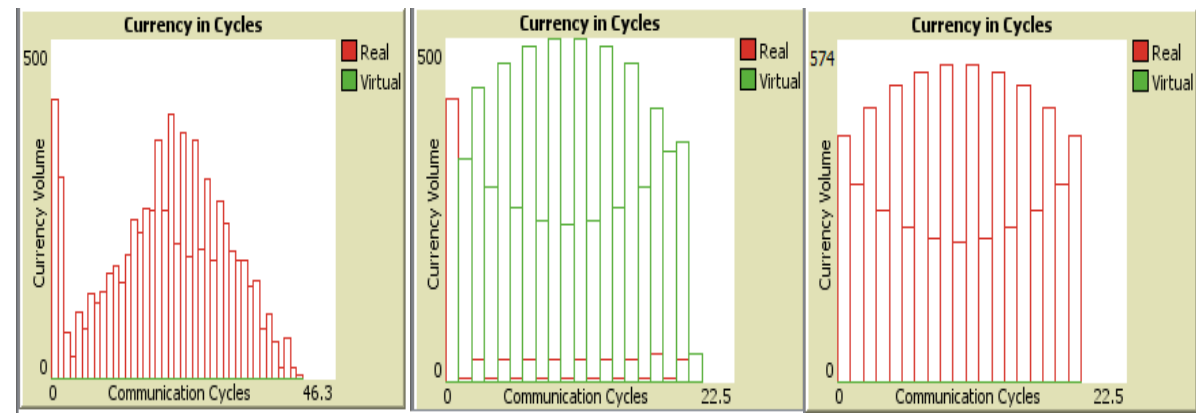

a) $k_{\text {mon }}=0.1 ; k_{v m o n}=0$

b) $k_{\text {mon }}=0.1 ; k_{v m o n}=0.4$

c) $k_{\text {mon }}=1.0 ; k_{v m o n}=0$

Fig. 2. Money turnover in the system for the second data set: external (real) currency (red), internal or virtual (complementary) currency (green). 


\section{Economic experiments in the local business community}

To carry out the economic experiment a local business community from the agricultural region of Bashkortostan republic was chosen. This region is in $40 \mathrm{~km}$ far from Ufa, there are several small manufacturing firms and service sector enterprises in the five closely located villages. Agricultural output and products manufactured from it comprise the economic basis of the community. The aggregated indicators of the community are as follows:

- the number of employees is under 200 persons;

- the business activity types are as follows: crop farming, cattle breeding, trading, agricultural machinery services;

- the area of cultivated land is 8000 hectares, the area of arable land is 6000 hectares;

- the cattle number is 1200 ;

- the level of capitalization is 330 million rubles.

At the beginning of the experiment, the community was in a depressive state, as bank loan debts were growing, there were almost no cash for salary payment and the salary debt was greater than for three months, thus, all of this resulted in the social tension increase.

In the period of 2010-2013 three economic experiments on commodity exchange were carried out in the territory of the community on base of the complementary currency usage. The complementary currency was fully supported by the locally manufactured product and trade residues in local shops.

The largest local enterprise of the community, "Shaymuratovo Ltd.", has become an emission center of complementary currency. It issued the local currency (product checks) in the cash form, this currency was named "shaimuratics". Every year product checks of the previous issue were withdrawn from the turnover and replaced by the new ones. The annual issue of the complementary currency was in the ranks of 100 thousand to 400 thousand rubles.

There were no restrictions on the complementary currency usage: it was used for salary payments as well as for mutual payments between entrepreneurs. The complementary currency usage was a freewill case: every community member in any day had a possibility to receive the necessary currency volume (no more than his/her salary amount). That is why "shaimuratics" were in demand in the case when there was a lack of ruble cash for supporting the turnover. Ruble and complementary currency turnover control was executed when they were paid (in the enterprises cash-desks) and when they were received as payments for products and services (in the shops cash-desks, and etc.). All data about the complementary currency and rubles turnover was aggregated for a week. It gave a possibility to estimate how many rubles and "shaimuratics" were involved in the turnover for a week. The turnover diagram is presented in Figure 3. Turnover scales are made comparable (look at the left and right range) for better visual illustrating of revealed synergetic effect which arose due to the currencies joint use.

It is evident from Figure 3 that it took at about 5 weeks "to launch" the turnover, during this period the community members were studying to use the new type currency. Later on, the turnover demonstrated the tendency towards the growth, it was true for rubles and also for the local currency. At the same time, in the neighbor communities which used only rubles the turnover was continuously decreasing. The week level of turnover has the strongly marked season characteristic: the $29^{\text {th }}-32^{\text {nd }}$ week peak became the result of the New Year eve, then one can see the drop (the $33^{\text {rd }}$ week) because of activity decrease while the winter vacations.

From the diagram one can comprehend that in the periods when there was the lack of rubles in the community, it was compensated by the complementary currency, and vice versa, when the rubles volume was large enough, the necessity in the complementary 
currency became less. Thus, complementary currency in a local business community acts as an addition and in compliance with the national (real) currency.

While the experiment, the complementary currency usage provided sustainable development of the local business community according to the following parameters:

- commodity turnover has been increased twelve times;

- productivity has been increased by 20 percent;

- all salary debts were repaid;

- average salary level has been increased by 26 percents.

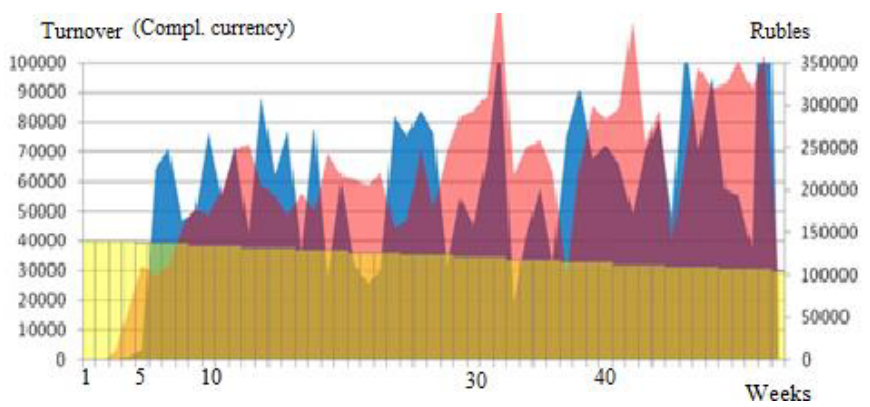

Fig. 3. Comparable dynamics of the local community commodity turnover of the complementary currency (is shown in blue color, left range) and Russian rubles (is shown in red color, right range) in terms of week specification (Data was collected in 2010-2011).

\section{Conclusion}

The two types experimental results (in the computer simulation and in the real economic experiment) show that introduction of complementary currency removes the restrictions arisen in the local business communities because of the cash outflows to financial centers of globalization and, thus, results in creation of the conditions for sustainable development of regions.

The mechanisms of the complementary currency, which positively influence the community economics, are as follows. Although there are money outflows to financial centers of globalization, there are capital goods, labor force, local resources and consumer demands in the local territory. But the consumer demand occurs to be a potential one, because there are no instruments of payment (cash). Complementary currency helps to solve this problem, it enables local products purchasing, local enterprises get the possibility to increase production, can exchange with local providers, and also begin to pay salaries in complementary currency. Later on, this reproduction cycle is repeated. A lot of enterprises due to product sale for complementary currency can operate above the breakeven point, which is impossible in the conditions of payments in the national cash.

The synergetic effect of simultaneous currencies usage was revealed: complementary currency does not compete with the national currency, it acts in compliance with it providing the conditions for sustainable development of a community as a whole.

\section{Acknowledgements}

Present study was carried out under financial support of the Russian Fund of Fundamental Research grant № 15-06-04863 “Mathematical models of local payment system lifecycles”. 


\section{References}

1. K.H. O'Rourke, J.G. Williamson, NBER Working Paper Series, 7632 (April 2000). http://www.nber.org/papers/w7632.pdf

2. International Monetary Fund. IMF Publications (April 2000). http://www.imf.org/external/np/exr/ib/2000/041200to.htm

3. P. Guinness, Geography for the IB Diploma Global Interactions (Cambridge, 2011)

4. I.G. Nordin, C. Zamorano Llena (eds), Redefinitions of Irish Identity: A Postnationalist Approach (Oxford, 2010)

5. B.A. Lietar, The Future of Money. Creating New Wealth, Work and Wiser World (Moscow, 2007)

6. C.M. Macal, M.J. North, Journal of Simulation, 4, 151-162 (2010)

7. V.V. Leontief, Essays in economics. Theories, theorizing, facts and policies (Moscow, 1990)

8. P.L. Borrill, L. Tesfatsion, Agent-Based Modeling: The Right Mathematics for the Social Sciences. Working Paper № 10023 (July, 2010)

9. NetLogo. http://ccl.northwestern.edu/netlogo

10. O.M. Zvereva, D.B. Berg, OPT-i 2014 - 1st International Conference on Engineering and Applied Sciences Optimization, Proceedings, 33-43 (2014)

11. D.B. Berg, O.M. Zvereva, A.G. Shelomentsev, A. Taubayev, Proceedings 15th International Multidisciplinary Scientific Geoconference SGEM 2015. Ecology, Economics, Education and Legislation, Vol. 3, 109-118 (2015) 